\title{
Light and electron microscopic studies on some lymph nodes of the adult one-humped camel (Camelus dromedarius)
}

\author{
S. M. Soliman, K. M. Mazher \\ Department of Cytology and Histology, Faculty of Veterinary Medicine \\ Beni-Suef University, Beni-Suef, Egypt
}

\begin{abstract}
Samples from medial retropharyngeal, superficial cervical and deep femoral lymph nodes of four camels were fixed in neutral buffered formalin and prepared for light and electron microscopic examination. The camel lymph nodes were formed of stroma and parenchyma. A dense collagenous capsule and trabeculae beside fine reticular framework represented the stroma. The parenchyma was formed of follicular and non-follicular forms of lymphoreticular tissue. The lymphoid follicles were mainly secondary in nature formed of germinal center and outer corona. Afferent and efferent lymph vessels were noticed at the same area of the capsule. Capsular, subcapsular, trabecular, peritrabecular and parenchymal lymph sinuses were noticed in camel lymph nodes.
\end{abstract}

The lymph nodes are major parts of the encapsulated lymphoreticular tissue designed to filter lymph (Ham, 1974). They are distributed throughout the body always along the course of lymphatic vessels that carry lymph into thoracic and right lymphatic ducts (Junqueira et al., 1986). The lymph nodes are found in the axillas and in the groin along the great vessels of the neck and in large number in thorax and abdomen especially the mesentery. Weiss (1972) mentioned that the lymph nodes constitute a series of in-line filters whereby all tissue fluids derived lymph is filtered by at least one lymph node prior to its return to the circulatory system. The lymph enters the lymph node through afferent lymph vessels, which join the node at its convex surface. After the lymph has cleared and filtered, it leaves the node via efferent lymph vessel from the hilum (Nopajaroosri et al., 1971 and Ham, 1974).

Lymphocytes and macrophages are the main active cells in the lymph node as they carry out the clearance and filtration of lymph inside the lymph node (Junqueira et al., 1986).

This study aims to clarify the histological and the fine structure of camel lymph nodes in correlation to their function.

\section{Material and Methods}

The medial retropharyngeal, superficial cervical and deep femoral lymph nodes were collected from four adult camels.

For LM study, small pieces of tissues, from each lymph node were cut, immediately immersed in neutral buffered formalin for $24 \mathrm{hr}$. Paraffin sections of 4-6 micrometers-thick were obtained and stained by Harris hematoxylin and eosin, Crossmon's trichrome stain, Gomori's reticulin method and toulidine blue staint as outlined by (Drury and Wallington 1980).

For EM study $1 \mathrm{~mm}$ pieces of each lymph node were immersed in 3\% glutraldhyde in $1 \mathrm{M}$ phosphate buffer $(\mathrm{pH} ; 7.3)$ for $2 \mathrm{hr}$. Post fixed in cold $1 \mathrm{M}$ phosphate buffered $1 \%$ osmium tetroxide ( $\mathrm{pH}=7.3)$ for 3 hours, and then briefly rinsed in distilled water (Hayat, 1986).

Ultra thin sections were cut, mounted on copper grids and stained in 5\% uranyl acetate dissolved in $70 \%$ ethanol followed by lead citrate stain (Reynold, 1963). Mounted stained grids were examined in a Joel 100CX transmission electron microscope at $60 \mathrm{KV}$.

\section{Results}

The examined camel lymph nodes appeared as encapsulated spheroid multilobulated organs. Each was composed of stroma and parenchyma.

\section{Stroma.}

Each lymph node was surrounded by a thick and dense collagenous capsule from which thick trabeculae penetrated the organ (Fig. 1). The fibrous stroma divided the lymph node into nearly separated lobules (Fig. 2). The reticular stroma was presented by fine reticular framework ensheathed by satellite reticular cells united with the fibrous stroma and extending throughout the node, providing scaffolding in which immunocompetent cells were freely 
suspended. The reticular framework was extensive in the non-follicular tissue, moderate in the corona of lymphoid follicles and scanty in the germinal centers (Fig. 3). The fibrous stroma contained small blood vessels and capsular and trabecular lymph sinuses. The sinuses appeared as wide irregular lymph spaces lined by endothelial cells and numerous macrophages (Fig. 4). Both afferent and efferent lymph vessels were noticed in the same area of the fibrous capsule of lymph node (Fig. 5).

\section{Parenchyma.}

The parenchyma of the camel lymph nodes was clearly demarcated into follicular and nonfollicular forms of lymphoreticular tissue.

The follicular part was formed of large irregular or oval basophilic patches present mainly at the periphery of the lobule. These lymph nodules were secondary in nature formed of a lightly stained germinal center surrounded by densely stained corona (Fig. 6). The germinal center was formed of widely separated cells including large lymphocytes, macrophages, plasma cells, mast cell and dendritic cells while the cells of the corona were mostly small lymphocytes with few macrophages (Fig. 7). The macrophages of both corona and germinal center were medium-sized cells with irregular plasma membrane and kidney-shaped nuclei. The cytoplasm was filled with secondary lysosomes, well-developed rough endoplasmic reticulum and numerous mitochondria (Fig. 8). The secondary lysosome in the macrophages of adult camel lymph node was characterized by the presence of different electron dense materials that vary in their electron density (Fig. 9). The lymphocytes of the germinal center (immunoblasts) showed oval euchromatic nuclei surrounded by a wide electron lucent zone (Fig. 10). These cells were filled with well-developed rough endoplasmic reticulum.

The diffused non-follicular lymphoreticular tissue was formed of lymphocytes, macrophages, plasma cells and small cells with condensed nuclei (Fig. 11). These cells were supported by fine extensive reticular framework and reticular dendritic cells. Numerous parenchymal lymph sinuses appeared as wide irregular lymph spaces lined by endothelial cells and numerous macrophages (Fig. 12). Many small blood vessels were noticed in the nonfollicular form (Fig. 13). Some of these blood vessels were lined by high endothelium and were surrounded by epithelial reticular cells. The macrophages in the nonfolicular lymphoreticular tissue showed characteristic nuclei and their cytoplasm contained many lysosomes (Fig. 14). Some primary lysosomes were seen engulfing foreign body (Fig. 15). Some of the examined lymph nodes showed special organized structure surrounded by thin connective tissue capsule and contained blood vessel and multinucleated giant cell (Fig. 16).

\section{Discussion}

Unlike other animals, the lymph node of camel appeared spheroid and multilobulated while in other mammals the lymph node is kidney or bean shaped (Ham, 1974). The lymph node of camel was supported by a dense fibrous framework carryies blood and lymph vessels, sinuses and serves as site of entry of lymph vessels (Taher 1963; Taher et al., 1979; Emery and Fay, 1973; Boseila et al., 1981 and Junqueira et al., 1986). Our finding that both afferent and efferent lymph vessels enter and leave the node at the same area was in agreement with the findings of Taher (1963) and Taher et al. (1979).

As mentioned by Taher (1963), Taher et al., (1979) and Junqueira et al., (1986) the parenchymatus elements were supported by fine reticular framework. The germinal center of a lymph nodule appeared scanty or poor in these reticular fibers, whereas, the corona of the same nodule was very rich in such fibers.

The parenchyma of camel lymph nodes was formed of follicular and non-follicular forms of lymphoreticular tissue. The same result was desribed by (Taher, 1963 and Taher et al., 1979) in the camel. On the other hand Junqueira et al. (1986) mentioned that the parenchyma of lymph nodes of other animals except pig was formed of cortex and medulla.

The lymphoid follicles of our studied cases were mainly secondary in nature. The appearance of secondary follicles is a response to previous exposure to antigens (Dellman and Brown, 1976; Zhang et al., 2004 and Shiraki et al., 2004). The secondary lymphoid follicle was formed of an outer darkly stained corona and an inner lightly stained germinal center. The same results were reported by (Taher, 1963; Taher et al., 1979 and Junqueira et al., 1986). The cellular component of lymphoid follicle is mainly lymphocytes, macrophages, plasma cells and mast cells beside the denderitic cells (Dellman and Brown 1976 and Taher, et al., 1979). 


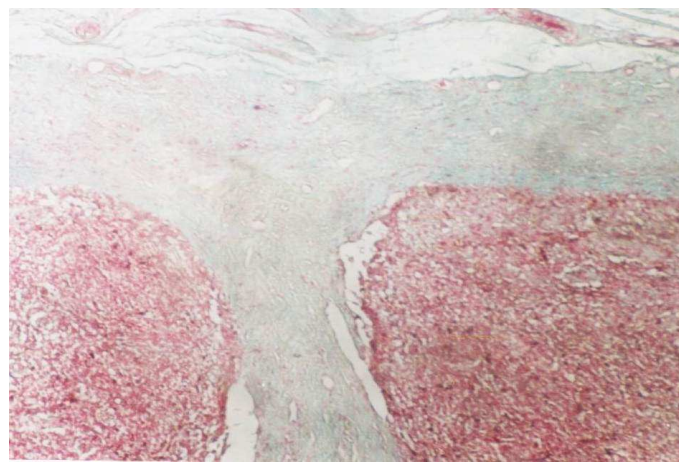

Fig. (1): A section in camel deep femoral lymph node showing a thick fibrous capsule and a trabeculum. Crossmon's trichrome stain (x100).

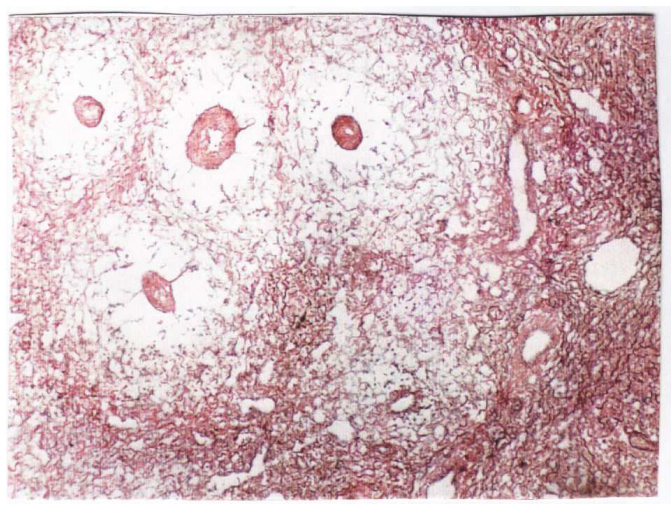

Fig. (3): A section in camel deep femoral lymph node showing extensive reticular network in the diffused form, moderate in the corona and very few in the germinal center. Gomori's reticulin method $(x 100)$.

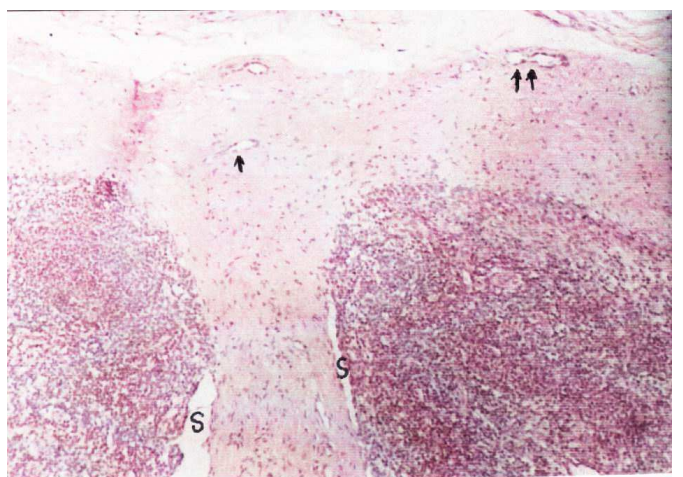

Fig. (5): A section in camel superficial cervical lymph node showing afferent lymphatics (arrow) and efferent vessel (double arrow) in the same area of the capsule. Notice the peritrabecular lymph sinuses (S). H\&E stain (x100).

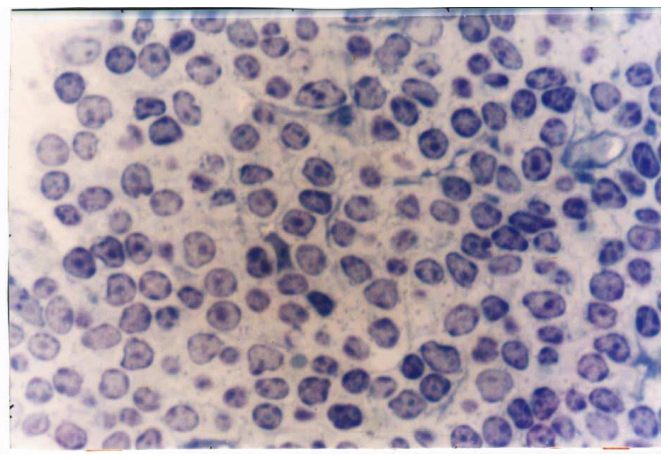

Fig. (7): A section in camel superficial cervical lymph node showing a part of the germinal center (left) of lymphoid follicle and a small part of the corona (Right). Toulidine blue stain $(\mathbf{x 1 0 0 0 )}$.

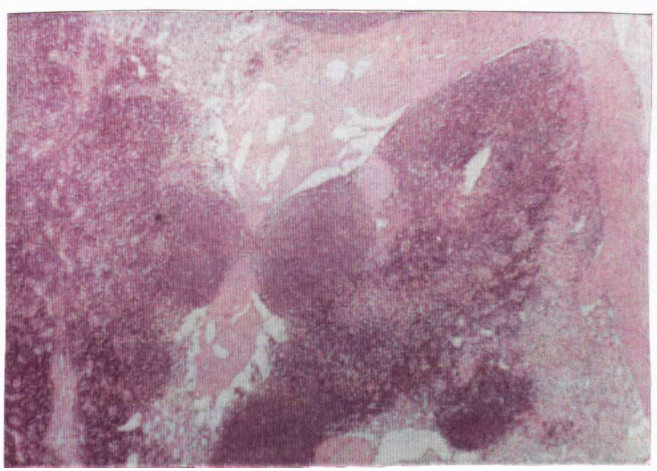

Fig. (2): A section in camel retropharyngeal lymph node showing fibrous stroma that divides the node into non isolated compartment. H \&E stain (x40).

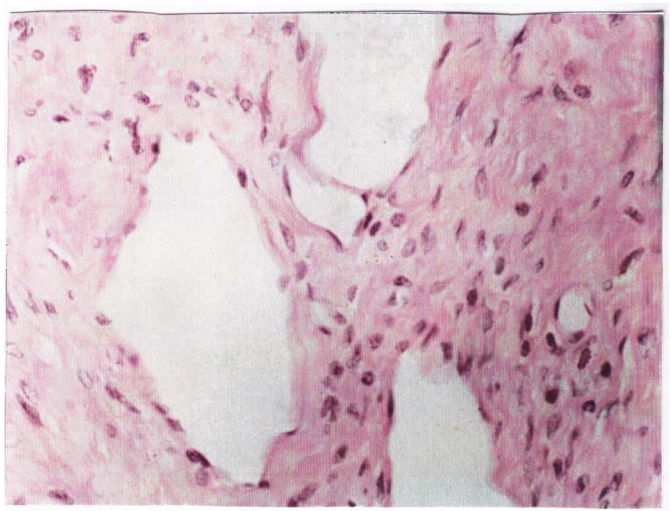

Fig. (4): A section in camel deep femoral lymph node showing trabecular lymph sinuses. H\&E stain $(x 400)$.

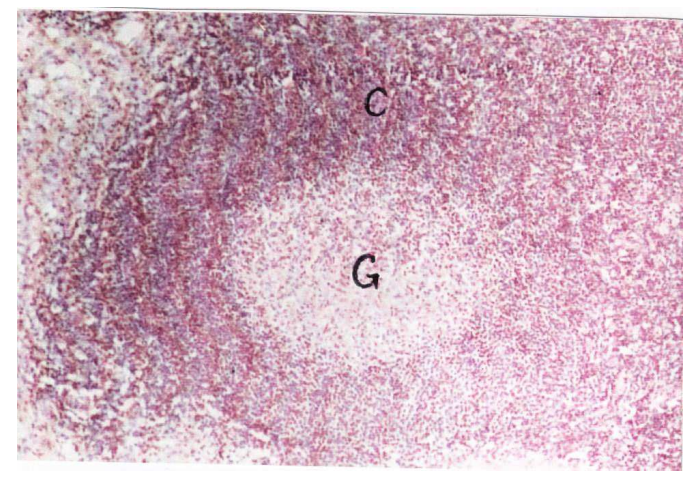

Fig. (6): A section in camel deep femoral lymph node showing a secondary lymphoid follicle having a light germinal center (G) and an outer dark corona (C). H\&E stain (x100).

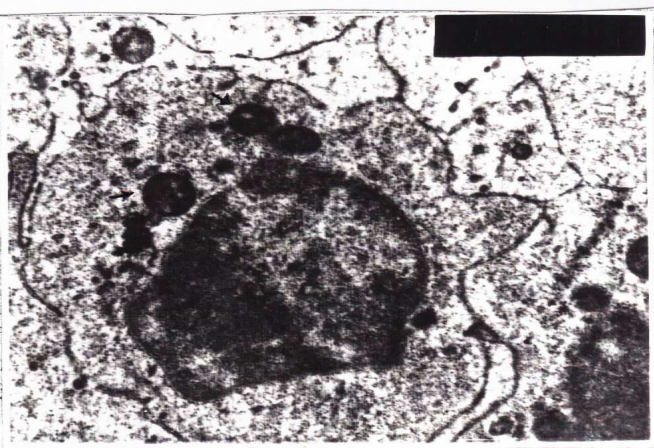

Fig. (8): An electron micrograph of the germinal center showing a macrophage with an oval nucleus and many lysosomes (arrow). Uranyl acetate-lead citrate (x6700). 


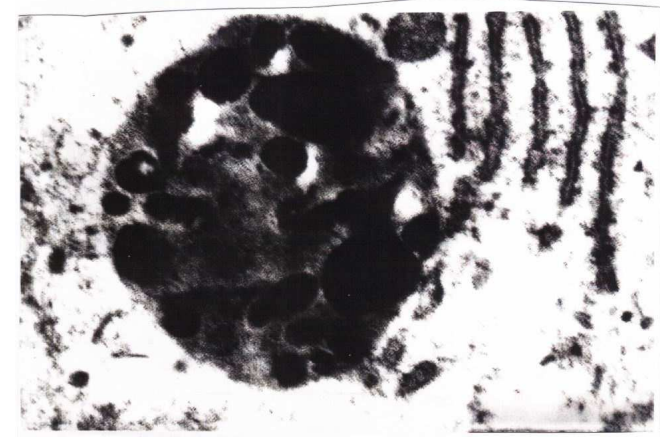

Fig. (9): A higher magnification of electron micrograph of macrophage showing a large secondary lysosome containing engulphed materials. Uranyl acetate-lead citrate (x20000).

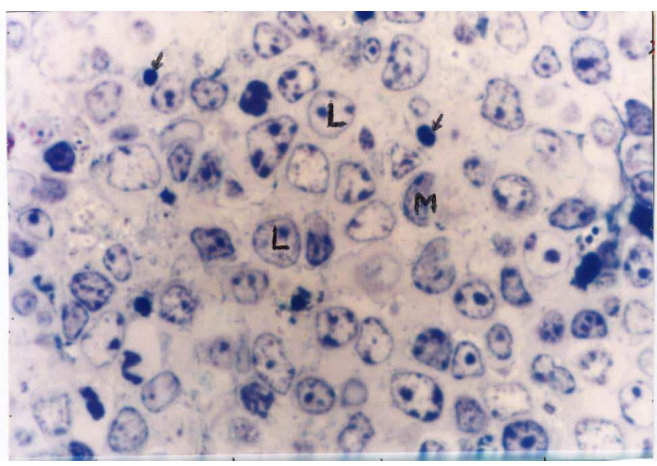

Fig. (11): A section in camel deep femoral lymph node showing non-follicular form containing widely separated lymphocyte $(L)$ macrophages (M) and small cells with condensed nuclei (arrow). Toulidine blue stain $(\mathbf{x 1 0 0 0})$

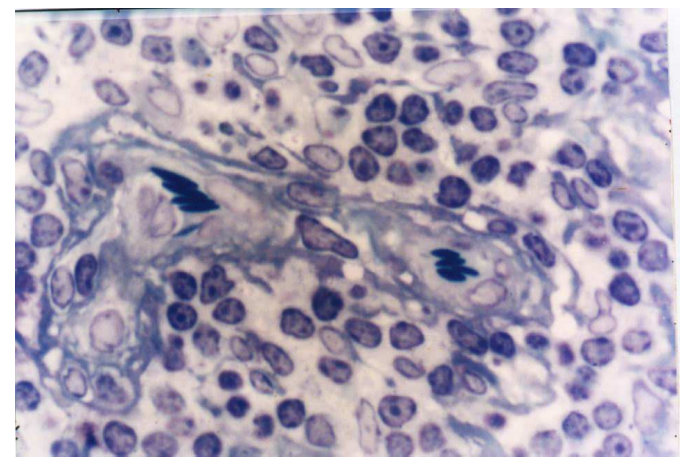

Fig. (13): A section in camel deep femoral lymph node showing small blood vessels lined by high endothelium (arrows) and surrounded by reticular cells in the non-follicular lymphoreticular tissue. Toulidine blue stain (x1000).

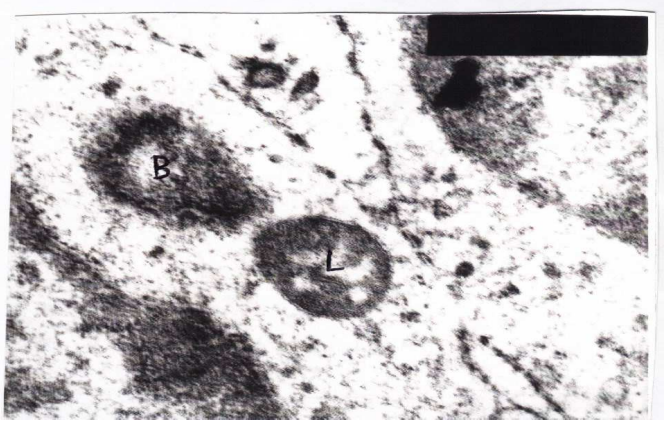

Fig. (15): A higher magnification of electron micrograph of a macrophage showing primary lysosome $(L)$ begin to engulf a foreign body (B). Uranyle acetate-lead citrate $(\mathbf{x 2 0 0 0 0 )}$.

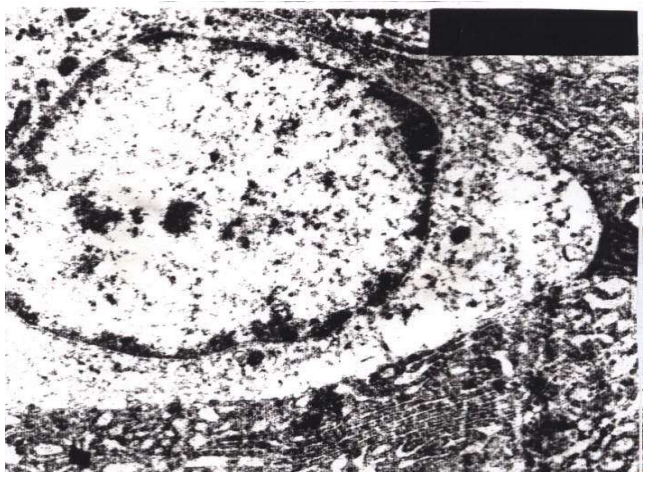

Fig. (10): An electron micrograph of a nodular lymphocyte containing an extensive network of rough endoplasmic reticulum. Notice the electron lucent zone surrounding the nucleus. Uranyl acetate-lead citrate (x8000).

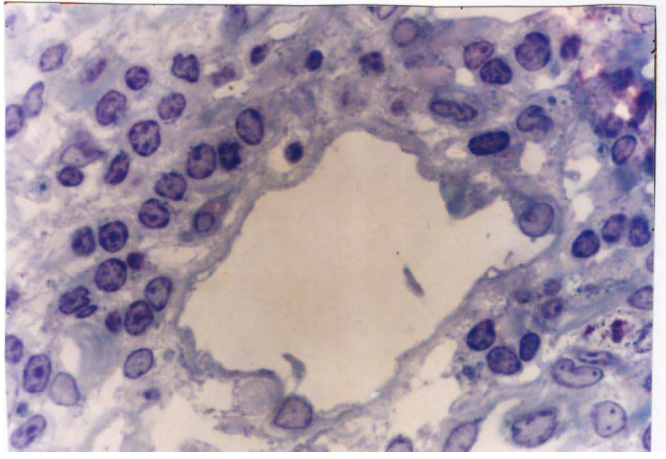

Fig. (12): A section in camel retropharygeal lymph node showing a wide irregular parenchymal lymph sinus. Toulidine blue stain $(\mathbf{x 1 0 0 0})$

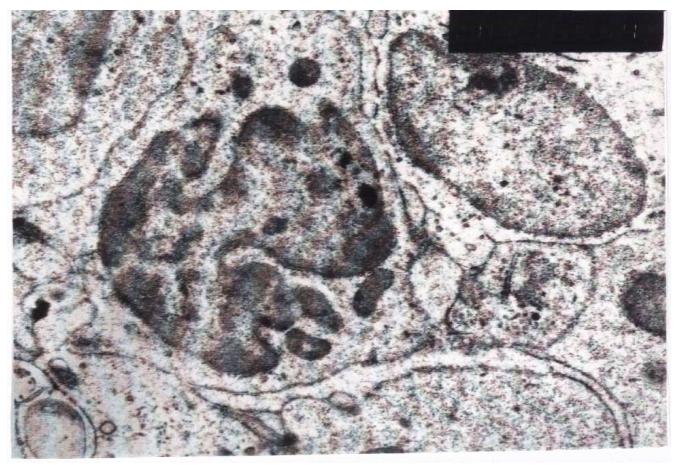

Fig. (14): An electron micrograph of the non-follicular part of the deep femoral lymph node showing a macrophage with characteristic nucleus. Uranyle acetate- lead citrate $(\mathbf{x 5 0 0 0})$.

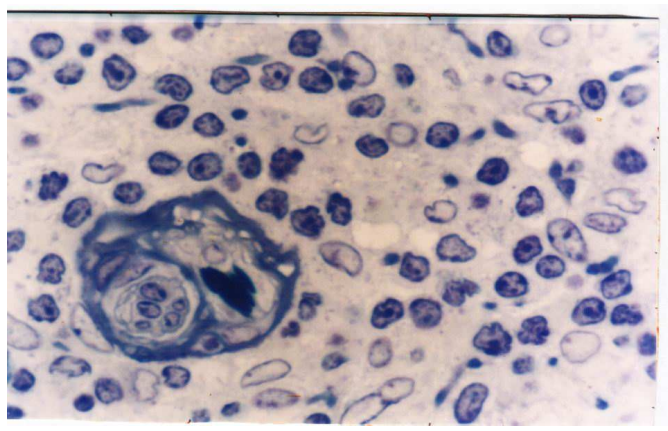

Fig. (16): A section in camel retropharyngeal lymph node showing a blood vessel and a giant multinucleated cell surrounded by a thin connective tissue capsule. Toulidine blue stain $(\mathbf{x 1 0 0 0 )}$. 
The denderitic cells beside their role in immune response form a cytoplasmic net that support the free cells mainly in the germinal center compensatory the absence of reticular fibers (Taher, 1963; Taher et al., 1979 and Fawcett, 1986). In agreement with (Han, 1961) and Nopajaroosri, 1971), the macrophage of the lymphoid follicles posses an oval or kidney shaped nucleus and several secondary lysosomes. On the other hand the macrophage of non-follicular lymphoid tissue posses many lysosomes with characteristic slightly segmented nucleus, which is lost in the literatures regarding other animals. The macrophages either in follicular or in non-follicular parts act as phagocytic cells engulf any foreign body or antigen then hydrolyse it inside their lysosomes (Ham, 1974; Fawcett, 1986 and Junqueira et al., 1986). The small lymphocytes of both follicular and non-follicular lymphoid tissue were occupied by large spherical nuclei and the cytoplasm filled with well-developed rough endoplasmic reticulum, primary and secondary lysosomes. Similar findings were reported by (Han, 1961; Nopajaroosri, 1971 and Fawcett, 1986).

In agreement with (Taher, 1963 and Taher et al., 1979) the lymph sinuses of camel lymph nodes were capsular, subcapsular, trabecular, peritrabecular and parenchymal lymph sinuses. Each lymph sinus appeared as a wide and irregular space lined by endothelial cells and many macrophages that in agreement of (Ham, 1974 and Fawcett, 1986).

Our study revealed the presence of high endothelium small blood vessels surrounded by dendretic cells in the non-follicular lymphoid tissue of lymph node. The same result was mentioned by (Taher, 1963; Nopajaroosri et al., 1971 and Junqueira et al., 1986). The latter authors stated that such blood vessels, might act as a mean of migration of lymphocytes to and from the lymph nodes.

The presence of giant cell near blood vessel could be interpreted as these camels might be exposed to strong antigen for prolonged time. (Janqueira et al., 1986; Fawcett, 1986; Samantaray et al., 2003 and Zhang et al., 2004) chronic exposure to antigen many giant cells were formed inside the lymph node. The appearance of thin capsule around the giant cell and blood vessel may provide evidence of long term of exposure.

\section{References}

Boseila, A.; Hashem, S. and El-Saie, A. (1981): Postnatal development of stroma in some lymphoid organs of albino rat. Egypt. J. Histol., 4 (2): 159

Dellman, H. D. and Brown, E. M. (1976): Textbook of veterinary histology. Lea and Febigar, Philadelphia.

Drury, R .A. B. and Wallington, E. A. (1980): Carlton's Histological technique. $4^{\text {th }}$ ed. London, New York, Toronto, Oxford Univ. Press.

Emery, J. and Fay, D. (1973): The postnatal development of lymphoreticular aggregates and lymph nodes in infant's lung. J. Clin. Path., 26: 539

Fawcett, D. W. (1986): A textbook of histology. $11^{\text {th }}$ ed. WB.Sounders Company, London, Toronto \& Hong Kong.

Ham, A. W. (1974): Histology. Seventh ed. Lippincott, Philadelphia and Montrial, 335-365

Han, S. S. (1961): Ultrastructure of mesenteric lymph node of rat. Am. J. Anat., 109: 183-225

Hayat, M. A. (1986): Basic techniques for transmission electron microscope. Academic Press, Inc. Florida, $1^{\text {st }}$ ed.

Junqueira, L.; Carneiro, J. and Long, J. (1986): Basic Histology. Atext book Librairie du Liban $5^{\text {th }}$ ed.

Nopajaroosri, C.; Luch, S. C. and Simon, G. T. (1971): Ultrastructure of normal lymph node. Am. J. Path., 65.

Reynolds, E. S. (1963): The use of lead citrate at high PH as an electron opaque stain in electron microscopy. J. Cell. Biol., 17: 208-212

Samantaray, S.; Rout, N.; Mallik, R. and Nayak, P. (2003): Metastasis of phylloides tumour to axillary lymph node. Indian J. Pathol. Microbiol. 46 (2): 281

Shiraki, N.; Hara, M.; Ogino, H.; Lida, A.; Tamaki, T. and Eimoto, T. (2004): False positive and true negative hilar and mediastinal lymph node FDG-PET radiologicalpathological correlation. Ann. Nucl. Med., 18 (1): 23-8

Taher, E. S. (1963): Study of lymph nodes of camel. Ph. D. Thesis, Fac, Vet. Med. Cairo Univ.

Taher, E. S.; Kandil, M. H. and Mosallam, E. S. (1979): The medial retropharyngeal lymph node of camel. Egypt. J. Histol., 2 (1): 63

Weiss, L. (1972): The cells and tissues of immune system. Prentice Hall.

Zhang, J. W.; Xu, J.; Zhao, X. and Jia, S. S. (2004): Morphology and immune response against cancer in cervical lymp node. Zhonghua Er Bi Yan Hou Ke Za Zhi, 39 (4): 223-226. 